\title{
Effect of Oxygen Partial Pressure and Sintering Temperature on the Evaporation of Elements during Sintering in In-Sn-Zn-O Transparent Conducting Oxide Systems
}

\author{
Dokyum Kim, Hyunil Jo, Young-Woo Heo, Jeong-Joo Kim, and Joon-Hyung Lee* \\ School of Materials Science and Engineering, Kyungpook National University, Daegu 41566, Republic of Korea
}

Received November 22, 2018; accepted December 3, 2018

\begin{abstract}
An amorphous In-Sn-Zn-O (ITZO) thin film has high electrical properties and is less prone to cracking in repeated bending, which is advantageous for application to flexible display panels. When ITZO sputtering target is sintered at high temperatures, the original compositions often deviate from the stoichiometry due to volatilization of $\mathrm{In}, \mathrm{Sn}$ and $\mathrm{Zn}$. In order to minimize the evaporation, targets have been sintered in high oxygen atmospheres. We investigate the volatile-induced compositional deviation of the ITZO samples after sintering. An electron probe micro-analyzer (EPMA) depth profile of the composition and thermogravimetric weight loss at high temperature were analyzed. The results showed that the sintering of ITZO at high oxygen partial pressure is very effective to suppress the volatilization of In, Sn, and Zn. The electrical and optical characteristics of the ITZO thin films are also analyzed.
\end{abstract}

Keywords: Amorphous thin film, Evaporation, Sintering, Oxygen partial pressure

\section{Introduction}

Thin films using Transparent Conducting Oxide (TCO) can provide high electrical conductivity and optical transparency in the visible wavelength range. Based on these characteristics, TCO has recently been developed for use as an electrode in flexible display panels, LEDs, LCDs, solar cells, and photoelectric devices [1]. Indium Tin Oxide (ITO) thin films have been widely used in display panels. However, microcracks are easily formed and lead to electric breakdown when bent and unfolded repeatedly for the application to flexible display panels $[2,3,4]$. Therefore, it is necessary to develop a material that can overcome the disadvantage of ITO thin films.

On the other hand, it is known that amorphous TCO thin films are advantageous for flexible displays due to less cracking even in repeated bending compared with crystalline thin films [5]. In order to make any material amorphous, an entropy of the material needs to be increased as the number of constituent components increased. From this point of view, it is preferable to use a multi-component material in order to produce an amorphous thin film. Among them, In-Sn-Zn-O (ITZO) is a representative multi-component system which provides

*Corresponding author

E-mail: joonlee@knu.ac.kr amorphous TCO thin films.

Amorphous ITZO thin films are usually deposited by the sputtering process. Sputtering efficiency and physical properties of thin films are known to be affected greatly by target density (porosity), grain size, electrical conductivity, etc. [2,3,6-10]. The co-sputtering method using two or more kinds of targets is difficult to utilize due to many processing variables to be precisely controlled. However, the sputtering using a single target is much simple and advantageous in terms of economic and production efficiency.

When the thin film is deposited by the sputtering process, there could be some compositional deviations between the target and thin films. If the single target for sputtering is composed of multi-component and some of the components are easily volatile due to their high vapor pressures at high temperatures, it is necessary to maintain the target composition close to the stoichiometry as much as possible during sintering. However, in the case of ITZO, $\mathrm{In}_{2} \mathrm{O}_{3}, \mathrm{SnO}_{2}$, and $\mathrm{ZnO}$, which are used as raw materials, are easily volatilized due to high vapor pressure during sintering at high temperatures, thereby deviating from the stoichiometry composition after sintering [11-13].

In this paper, we choose two ITZO compositions of In:Sn:Zn = 4:1:4 and 7:1:5 in atomic ratio, which is known to have excellent transparency and electrical conductivity while maintaining the amorphous structure in the 
formation of ITZO thin films. Compositional deviations of the ITZO samples caused by volatilization during sintering was examined. Sintering was performed by a reaction sintering method which did not undergo calcination process but which had both synthesis and densification simultaneously. The phase development process and a microstructure after sintering were also examined. The optimum sintering condition of ITZO ceramics is suggested in this study.

\section{Experimental details}

ITZO samples were prepared by using raw chemicals of $\mathrm{In}_{2} \mathrm{O}_{3}$ (indium corporation USA, $99.99 \%$ ), $\mathrm{SnO}_{2}$ (high purity chem., JPN, $99.99 \%$ ), ZnO (high purity chem., JPN, $99.99 \%$ ). The raw materials for the ITZO compositions of In:Sn:Zn = 4:1:4 and 7:1:5 in atomic ratio were weighed and the mixtures were wet ball milled with $\mathrm{ZrO}_{2}$ balls and ethyl alcohol. The employed compositions are shown in a $\mathrm{In}_{1.5} \mathrm{O}-\mathrm{SnO}_{2}-\mathrm{ZnO}$ phase diagram (see Fig. 1) [14]. The dried powders were cold isostatic pressed into pellets at 100MPa. The densification behavior of the green pellets was monitored using a thermos mechanical analyzer (Bruker TD5000SA) in the temperature range up to $1400{ }^{\circ} \mathrm{C}$ at a heating rate of $5{ }^{\circ} \mathrm{C} / \mathrm{min}$. The green samples were reactive sintered at $1400-1550{ }^{\circ} \mathrm{C}$ for $2 \mathrm{~h}$ in air or oxygen atmosphere at a heating rate of $5^{\circ} \mathrm{C} / \mathrm{min}$.

X-ray diffraction (X'Pert PRO, PANalytical, Netherlands) was used to analyze phases of the sintered samples and deposited thin films. A FE-SEM (JSM-6701F, JEOL, Japan) was used for microstructure observation. In order to analyze evaporation-induced compositional deviation during sintering, the specimens were cut in half and the cross sections were polished. Then, semi-quantitative compositional analysis from the surface of the samples to a depth of $450 \mu \mathrm{m}$ was carried out by (FE-EPMA, field emission-electron probe micro-analyzer JXA-8530F, JEOL, Japan). The ion distribution in the samples was also

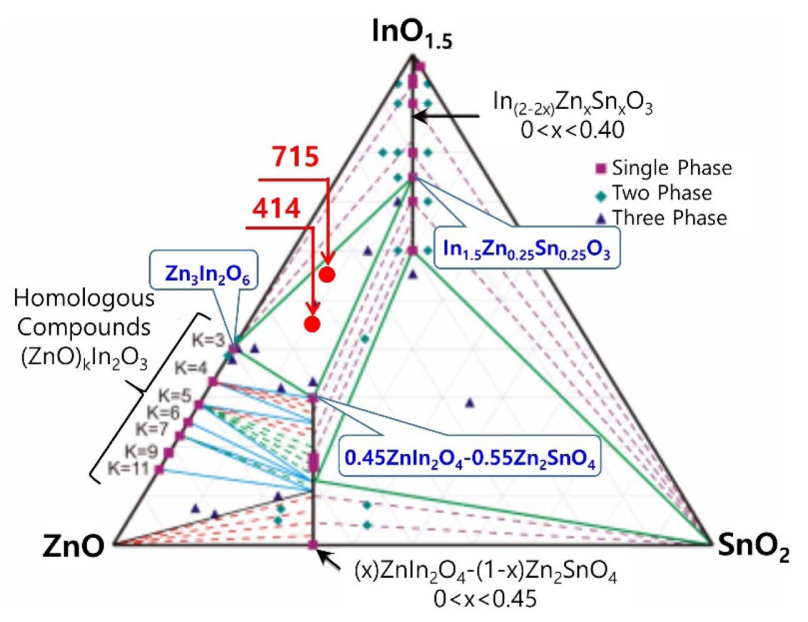

Figure 1. Phase diagram of the $\mathrm{InO}_{1.5}-\mathrm{SnO}_{2}-\mathrm{ZnO}$ system at $1275^{\circ} \mathrm{C}$. mapped out using the EPMA. Weight losses by the evaporation of the components were monitored using a thermogravimetric analysis (Q500, T.A. Instruments, USA) in air or oxygen. Electrical properties of thin films were measured by van der Pauw method at room temperature using Hall effect measurements (Ecopia, HMS-3000, Korea). Optical transmittance of the thin films was measured using a UV-Vis-NIR spectrophotometer (Cary 5000, Agilent, USA).

Prior to the deposition, the chamber was evacuated to a background pressure of $1.0 \times 10^{-6}$ Torr initially, and the working pressure during the film deposition was fixed to 5 mTorr by using $\mathrm{Ar}$ and $\mathrm{O}_{2}$ mixed gas (1000 / 1 ratio). Thin films were deposited at room temperature by RF-magnetron sputtering using a 2-inch diameter target sintered at $1550{ }^{\circ} \mathrm{C}$ in air or oxygen atmosphere. The distance between the target and the substrate was $65 \mathrm{~mm}$, and the RF power was kept constant at $50 \mathrm{~W}$. and pre-pre-sputtering and pre-sputtering were performed for $5 \mathrm{~min}$, respectively.

\section{Results and discussion}

Figure 2 shows the X-ray diffraction patterns of the 414 samples sintered at various temperatures in Fig. 2(a) air and Fig. 2(b) oxygen. Three kinds of phases were observed in all samples regardless of the sintering temperature and atmospheres, and the three phases were identified as $\operatorname{In}_{2-2 x}$ $\mathrm{Zn}_{\mathrm{x}} \mathrm{Sn}_{\mathrm{x}} \mathrm{O}_{3}$ (ITZO), $\mathrm{Zn}_{2-\mathrm{x}} \mathrm{In}_{2 \mathrm{x}} \mathrm{Sn}_{1-\mathrm{x}} \mathrm{O}_{4}$ (ZTO) and $\mathrm{Zn}_{3} \mathrm{In}_{2} \mathrm{O}_{6}$ (IZO). This phase development is predictable from the phase equilibrium shown in Fig. 1. The ITZO can be regarded as a phase in which $\mathrm{Sn}^{4+}$ and $\mathrm{Zn}^{2+}$ are co-doped in the $\mathrm{In}^{3+}$ site of $\mathrm{In}_{2} \mathrm{O}_{3}$ bixbyite structure, and the IZO phase observed was the $\mathrm{k}=3$ phase of $(\mathrm{ZnO})_{\mathrm{k}} \times \operatorname{In}_{2} \mathrm{O}_{3}[15$, 16]. The ZTO phase is a phase doped with $\mathrm{In}_{2} \mathrm{O}_{3}$ in
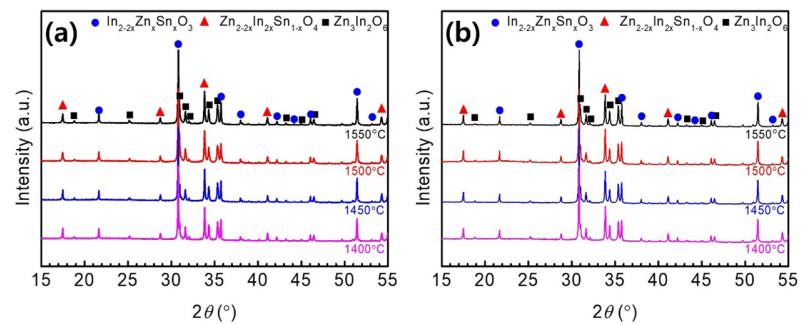

Figure 2. X-ray diffraction patterns of the 414 samples sintered at various temperatures for $2 \mathrm{~h}$ in (a) air, and (b) $\mathbf{O}_{2}$.
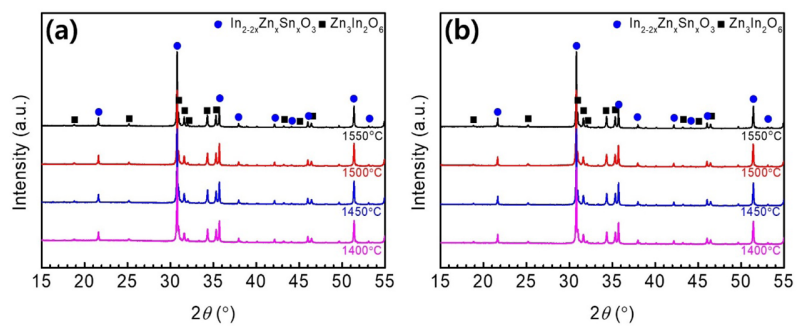

Figure 3. X-ray diffraction patterns of the 715 samples sintered at various temperatures for $2 \mathrm{~h}$ in (a) air, and (b) $\mathrm{O}_{2}$. 
$\mathrm{Zn}_{2} \mathrm{SnO}_{4}[17]$.

Figure 3 shows the X-ray diffraction patterns of the 715 samples sintered at various temperatures in Fig. 3(a) air and Fig. 3(b) oxygen. Although the results are not presented in this paper, the three phases, which were observed in the 414 , were also identified in the 715 sample when it was sintered at 1000 and $1200^{\circ} \mathrm{C}$. However, as the sintering temperature increased over $1400^{\circ} \mathrm{C}$, the ZTO phase disappeared and only the ITZO and IZO phases were observed. This is probably due to the shift of the tie line over $1400{ }^{\circ} \mathrm{C}$, which is higher than the temperature of the phase equilibrium at $1275^{\circ} \mathrm{C}$ [Fig. 1]. In the case of $\mathrm{x}=1$ on ZTO, a phase of spinel structure $\mathrm{ZnIn}_{2} \mathrm{O}_{4}$ can be formed [18] but no phase of $\mathrm{ZnIn}_{2} \mathrm{O}_{4}$ spinel structure was found in $\mathrm{ZnO}-\mathrm{In}_{2} \mathrm{O}_{3}$ phase [16]. In addition, the solubility limit of In for ZTO was found to be $\mathrm{x}=0.45$, that is, $\mathrm{Zn}_{1.55} \mathrm{In}_{0.9} \mathrm{Sn}_{0.55} \mathrm{O}_{4}$ at $1275^{\circ} \mathrm{C}$ [17]. As more In was added to ZTO phase at above $1400{ }^{\circ} \mathrm{C}$, it is confirmed that it is separated into IZO phase and ITZO phase which are not the $\mathrm{ZnIn}_{2} \mathrm{O}_{4}$ phase.

Figure 4 shows microstructure and element distribution of the 414 samples sintered at 1400 and $15500^{\circ} \mathrm{C}$ in the air. SE image corresponds to the secondary electron image
(SEM image) and BSE corresponds to the backscattered electron image. EPMA element maps are also presented. Figure 5 also shows the same placement of the photographs of the 715 samples sintered at 1400 and $1550{ }^{\circ} \mathrm{C}$ in the air.

When the 414 and 715 samples were sintered at $1400^{\circ} \mathrm{C}$, the mean grain size of the $414(6.1 \mu \mathrm{m})$ was larger than that of the $715(4.1 \mu \mathrm{m})$. When the samples were sintered at the higher temperature of $15500^{\circ} \mathrm{C}$, the mean grain size of both 414 and 715 increased to 8.9 and $7.5 \mu \mathrm{m}$, respectively, and the grain size of the 414 was still larger than that of the 715.

In the case of the 414 sample, as shown in Figs. 4(b) and $4(\mathrm{~g})$, there are three contrasts, as the three phases appear in the X-ray diffraction pattern shown in Fig. 2. Similarly, the composition of 715 shows two phases in the X-ray diffraction pattern of Fig. 3, which is consistent with that of Figs. 5(b) and 5(g). Based on the difference in contrast and the ratio of elements in each region, the darkest region of the 414 sample corresponds to the $\operatorname{IZO}\left(\mathrm{Zn}_{3} \mathrm{In}_{2} \mathrm{O}_{6}\right)$ phase, the medium dark region is ZTO $\left(\mathrm{Zn}_{2-\mathrm{x}} \mathrm{In}_{2 \mathrm{x}} \mathrm{Sn}_{1-\mathrm{x}} \mathrm{O}_{4}\right)$, and the brightest region is ITZO $\left(\operatorname{In}_{2-2 x} \operatorname{Sn}_{x} Z_{\mathrm{x}} \mathrm{O}_{3}\right)$. In the case of the 715 sample, the dark region corresponds to the IZO

Table I. The compositions of the three phases in the 414 sample.

\begin{tabular}{|c|c|c|c|c|c|c|c|}
\hline \multicolumn{4}{|c|}{$\begin{array}{l}\text { Fig. 4(b) } \\
\left(1400^{\circ} \mathrm{C}\right)\end{array}$} & \multicolumn{4}{|c|}{$\begin{array}{l}\text { Fig. } 4(\mathrm{~g}) \\
\left(1550^{\circ} \mathrm{C}\right)\end{array}$} \\
\hline \multirow[t]{4}{*}{ Brightness } & In & $\mathrm{Sn}$ & $\mathrm{Zn}$ & Brightness & In & $\mathrm{Sn}$ & $\mathrm{Zn}$ \\
\hline & 41.3 & 14.0 & 44.7 & & 44.4 & 7.2 & 48.4 \\
\hline & 39.4 & 24.8 & 35.8 & & 40.7 & 23.6 & 35.8 \\
\hline & 76.2 & 14.5 & 9.3 & & 74.8 & 15.3 & 9.8 \\
\hline
\end{tabular}

Table II. The compositions of the two phases in the 715 sample.

\begin{tabular}{|c|c|c|c|c|c|c|c|}
\hline \multicolumn{4}{|c|}{$\begin{array}{l}\text { Fig. 5(b) } \\
\left(1400^{\circ} \mathrm{C}\right)\end{array}$} & \multicolumn{4}{|c|}{$\begin{array}{l}\text { Fig. } 5(\mathrm{~g}) \\
\left(1550^{\circ} \mathrm{C}\right)\end{array}$} \\
\hline \multirow[t]{3}{*}{ Brightness } & In & $\mathrm{Sn}$ & $\mathrm{Zn}$ & Brightness & In & $\mathrm{Sn}$ & $\mathrm{Zn}$ \\
\hline & 46.5 & 7.6 & 45.9 & & 47.0 & 6.6 & 46.4 \\
\hline & 77.8 & 14.0 & 8.2 & & 76.3 & 15.1 & 8.6 \\
\hline
\end{tabular}

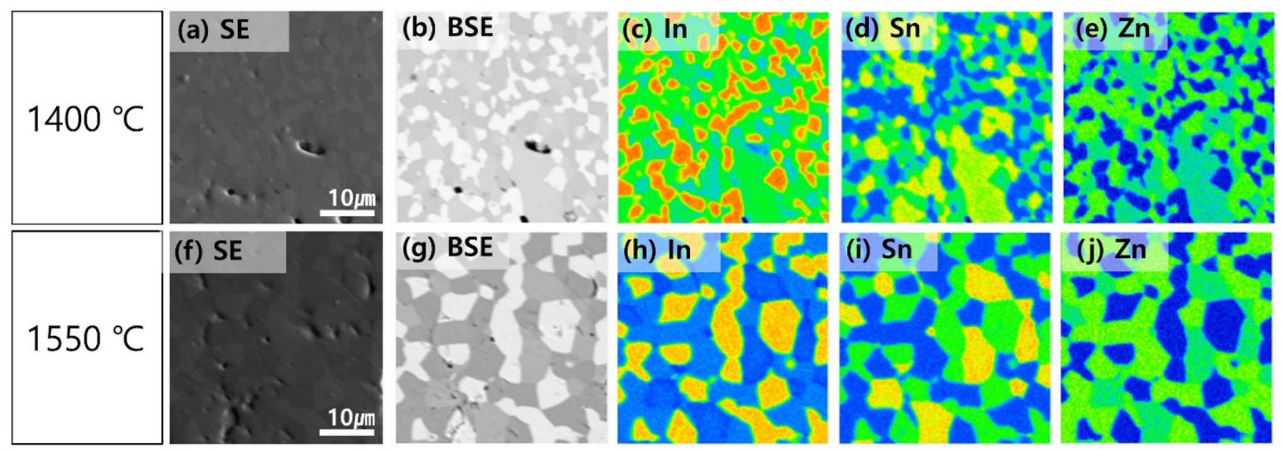

Figure 4. EPMA mapping of the 414 sample sintered in air at $1400{ }^{\circ} \mathrm{C}$ and $1550{ }^{\circ} \mathrm{C}$. 


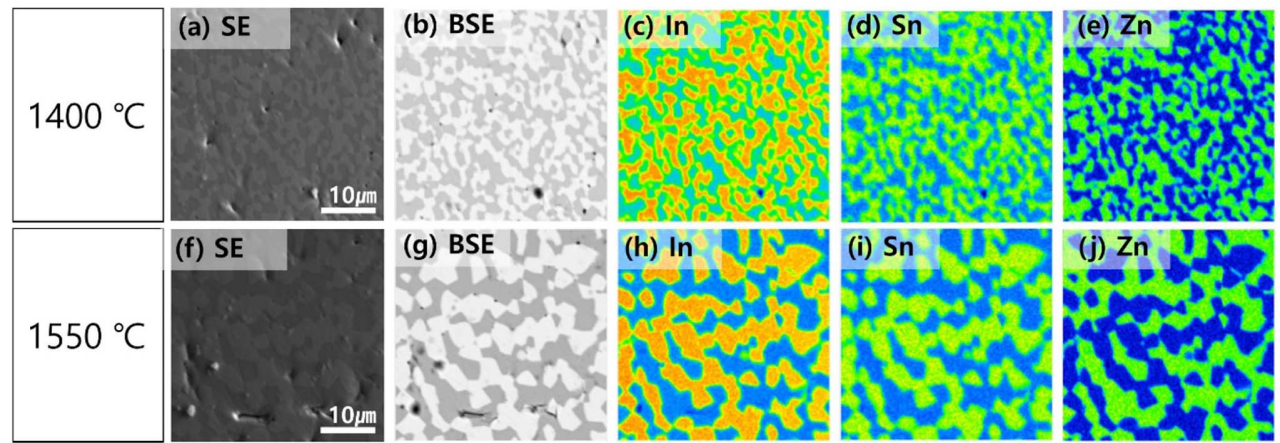

Figure 5. EPMA mapping of the 715 sample sintered in air at $1400{ }^{\circ} \mathrm{C}$ and $1550{ }^{\circ} \mathrm{C}$.

$\left(\mathrm{Zn}_{3} \mathrm{In}_{2} \mathrm{O}_{6}\right)$ and the bright region is ITZO $\left(\operatorname{In}_{2-2 x} \mathrm{Sn}_{\mathrm{x}} \mathrm{Zn}_{\mathrm{x}} \mathrm{O}_{3}\right)$.

The elemental compositions analyzed by EPMA at respective contrast regions are shown in Tables I and II. The ratio of In:Zn in the IZO region is close to $1: 1$, which deviates from the $2: 3$ of the theoretical ratio of IZO. In addition, the $\mathrm{Sn}: \mathrm{Zn}$ ratio in ITZO should be $1: 1$, but the analyzed elemental ratio does not match exactly. This is thought to be caused by the higher evaporation of $\mathrm{Zn}$ than In and Sn during thermal etching process after polishing for the EPMA sample preparation.

The equation of pressure depending on the temperature of each oxide is shown as Eq. (1) [19].

$$
\begin{gathered}
\mathrm{In}_{2} \mathrm{O}_{3}: \log P=16.478-\frac{27791}{T} \\
\mathrm{SnO}_{2}: \log P=18.6-\frac{28800}{T}
\end{gathered}
$$$$
Z n O: \log P=2.3\left(1300^{\circ} \mathrm{C}\right), 2.6\left(1400^{\circ} \mathrm{C}\right), 3.14\left(1500^{\circ} \mathrm{C}\right)
$$

Figures 6 and 7 show the depth profile of each
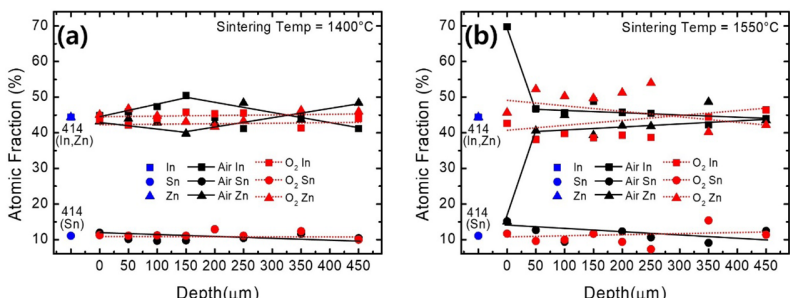

Figure 6. Atomic fraction of the $\mathbf{4 1 4}$ sample from the surface into the bulk interior after sintering in air or $\mathrm{O}_{2}$ at (a) $1400{ }^{\circ} \mathrm{C}$, and (b) $1550{ }^{\circ} \mathrm{C}$ for $2 \mathrm{~h}$.

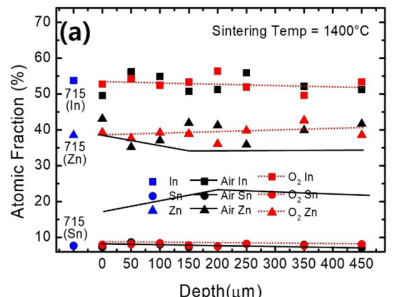

$\operatorname{Depth}(\mu \mathrm{m})$

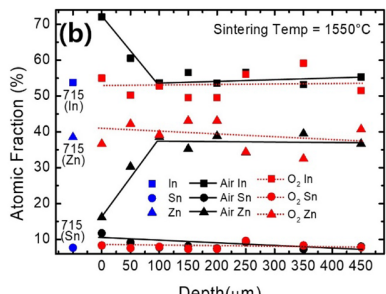

$\operatorname{Depth}(\mu \mathrm{m})$
Figure 7. Atomic fraction of the $\mathbf{7 1 5}$ sample from the surface into the bulk interior after sintering in air or $\mathrm{O}_{2}$ at (a) $1400{ }^{\circ} \mathrm{C}$, and (b) $1550{ }^{\circ} \mathrm{C}$ for $2 \mathrm{~h}$. constituent elements from the surface into the center of the 414 and 715 samples analyzed by EPMA. The data points are averaged by analyzing 10 different data points. However, the samples are composed of two or three phases having different atomic ratios, the data points could have a slight compositional error. In the figures, the blue dots show the compositions of the green body before sintering. Therefore, as the data points go away from the compositional ratio of the blue dots, the more volatilization occurred. In Fig. 6(a), which shows the elemental ratios of In, $\mathrm{Sn}$ and $\mathrm{Zn}$ in 414 sample sintered at $1400^{\circ} \mathrm{C}$ in air or $\mathrm{O}_{2}$, the data points are scattered within a certain compositional range which signifies that the compositional change is not significant compared with the original values. However, more detailed observations reveal that the sintering in the air has a greater compositional change than in sintering in $\mathrm{O}_{2}$. When the sample was sintesred at $1550{ }^{\circ} \mathrm{C}$ [Fig. 6(b)], the data points were scattered more disturbingly, especially at the surface when the sample was sintered in air. This phenomenon is caused by a considerable volatilization near the surface when sintering is conducted at a high temperature in air. Figures 7(a) and 7(b) show the case of 715 sample, which show very similar results with Fig. 6 that $\mathrm{O}_{2}$ atmosphere can suppress the volatilization of the elements.

Figure 8 shows the in-situ thermogravimetric analysis of the 414 and 715 samples during heating in air and $\mathrm{O}_{2}$. While the weight loss decreases slowly to approximately $1200{ }^{\circ} \mathrm{C}$, it begins to increase sharply over the temperature. In the case of the 414 sample in Fig. 8(a), there was no significant difference in weight loss regardless of the
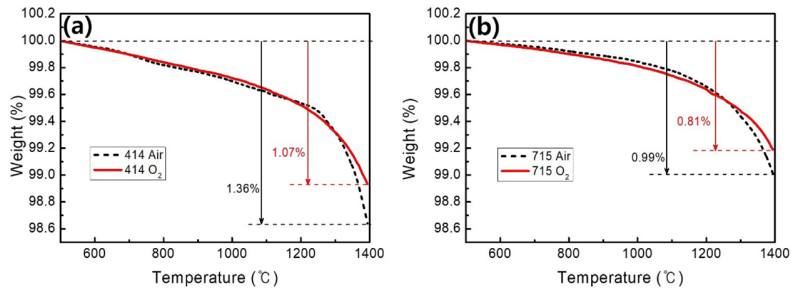

Figure 8. The thermogravimetry analysis show the evaporation induced weight loss of the (a) 414, and (b) 715 samples during heating in air and $\mathrm{O}_{2}$. 

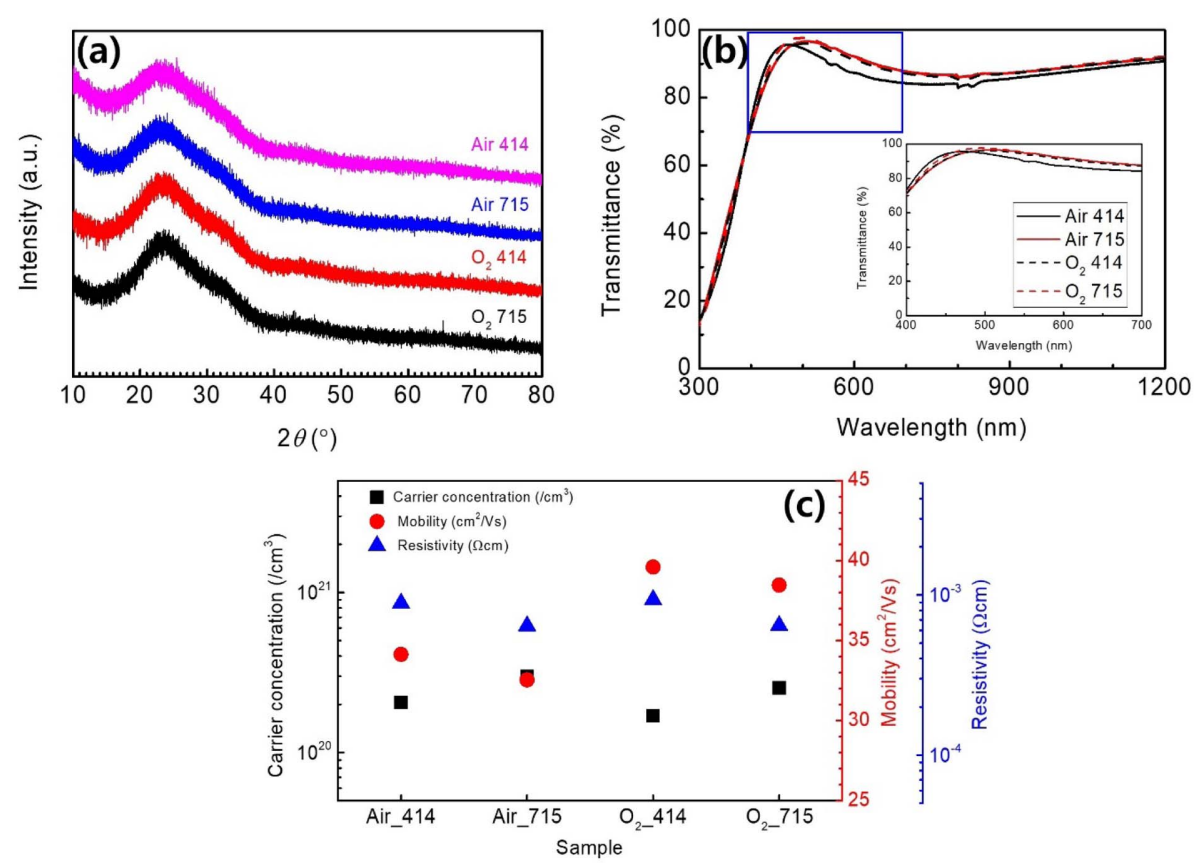

Figure 9. (a) X-ray diffraction patterns, (b) optical transmission spectra, and (c) variations of the carrier concentration, mobility and resistivity of the ITZO thin films deposited by the targets sintered at different conditions.

sintering atmosphere until $1300^{\circ} \mathrm{C}$. However, in higher temperatures over $1300{ }^{\circ} \mathrm{C}$, the weight loss sharply increased when the sample was sintered in air. Figure 8(b) shows the case of the 715 sample. The result is similar to the case of the 414 shown in Fig. 8(a). In the thermogravimetric analysis, the weight loss of the 414 sample was larger than that of the 715 sample, which is thought to be due to the easily evaporating higher $\mathrm{Zn}$ content in 414 than that of the 715 sample. Both the (a) and (b) show that the higher the sintering temperature, the more volatilization is. The lower the oxygen partial pressure during sintering, the more volatile the elements are. Therefore, it is necessary to control these sintering parameters during sintering of ITZO.

Figure 9 shows an XRD pattern, optical transmittance, and electrical properties of thin films deposited using the 414 and 715 targets sintered in different atmospheres of air and $\mathrm{O}_{2}$. As shown in Fig. 9(a), the X-ray diffraction patterns of the thin films are all in an amorphous state. The optical transmittance values of the thin films shown in Fig. 9 (b) were all higher than $90 \%$. Among them, however, the lowest transmittance was obtained in the case of 414 sample in which the weight loss was the greatest. The electrical characteristics of the thin films are presented in Fig. 9(c). Because the thin films were deposited in a fixed condition, the electrical characteristics are not optimized by controlling the deposition parameters. Nevertheless, it is difficult to compare with each other though, it is noteworthy that the carrier mobilities of the 414 and 715 thin films grown by the targets sintered in $\mathrm{O}_{2}$ were superior to the others.

\section{Conclusions}

In this study, the 414 and 715 samples were employed for a fabrication of amorphous thin films with high optical transmittance and electrical properties to be applied to flexible devices. After reaction sintering at $1400-1550{ }^{\circ} \mathrm{C}$, it was found that the 414 sample is composed of three phases of ITZO, IZO, and ZTO, while 715 sample showed only ITZO and IZO phases. The BEI of the samples which revealed clear contrast images showed a good agreement in the phase relations with the results of the X-ray diffraction.

EPMA mapping showed that $\mathrm{Zn}$ evaporates more easily than In and Sn. The EPMA depth profile showed that high sintering temperature and low oxygen partial pressure should be avoided during ITZO sintering. The results of the TG analysis showed a specific temperature range at which the weight loss rapidly increased and different weight loss values depending on oxygen partial pressure during sintering. As a result, it can be concluded that a high oxygen partial pressure is very effective for suppressing the volatilization of the elements of ITZO in order to maintain the stoichiometry.

The thin films grown by the targets sintered in $\mathrm{O}_{2}$ revealed higher optical transmittance and carrier mobility than the others.

\section{Acknowledgements}

This research was supported by the National Research Foundation of Korea (NRF) grant funded by the korean government (MSIP) (grantnumber NRF-2017R1A4A 1015022) and by Industrial Material Fundamental 
Technology Development Program funded By the Ministry of Trade, industry \& Energy (MI, Korea) (No. 10063473).

\section{References}

[1] A. Ambrosini, S. Malo, and K. R. Poeppelmeier, Chem. Mater. 14, 58 (2002).

[2] J. R. Lee, D. G. Kim, G. H. Lee, Y. H. Park, and P. K. Song, Met. Mater. Int. 13, 399 (2007).

[3] T. Sasabayashi, N. Ito, E. Nishimura, M. Kon, P. K. Song, K. Utsumi, A. Kaijo, and Y. Shigesato, Thin Solid Films 445, 219 (2003).

[4] H. L. Hartnagel, Semiconducting Transparent Thin Films (Institute of Physics Publishing, Bristol, UK, 1995).

[5] N. Ito, Y. Sato, P. K. Song, A. Kaijio, K. Inoue, and Y. Shigesato, Thin Solid Films 496, 99 (2006).

[6] S. T. Kim, J. H. Lee, J. Y. Yang, S. W. Ryu, J. S. Hong, W. P. Hong, J. J. Kim, H. M. Kim, J. M. Yang, and S.H. Park, J. Korean Phys. Soc. 50, 662 (2007).

[7] V. Sittinger, F. Ruske, W. Werner, C. Jacobs, B. Szyszka, and D. J. Christie, Thin Solid Films 516, 5847 (2008)

[8] S. K. Park, I. H. Jeong, W. K. Kim, and M. G. Kwak, Thin Solid
Films 397, 49 (2001).

[9] L. J. Meng and M. P. dos Santos, Thin Solid Films 322, 56 (1998).

[10] R. H. Horng, D. S. Wuu, Y. C. Lien, and W. H. Lan, Appl. Phys. Lett. 79, 2925 (2001).

[11] G. V. Samsonov, The oxide hand book (IFI/PLENUM, New York, 1982).

[12] J. M. Phillips, R. J. Cava, G. A. Thomas, S. A. Carter, J. Kwo, T. Siegrist, J. Krajewski, J. Marshall, W. Peck, and D. Rapkine, Appl. Phys. Lett. 67, 2246 (1995).

[13] H. G. Kim, J. G. Lee, and H. H. Park, Appl. Sci. Converg. Technol. $15,123(2008)$

[14] S. P. Harvey, K. R. Poeppelmeier, and T. O. Mason, J. Am. Ceram. Soc. 91, 3683 (2008)

[15] G. B. Palmer, K. R. Poeppelmeier, and T. O. Mason, Chem. Mater. 9, 3121 (1997).

[16] T. Moriga, D. D. Edwards and T. O. Mason, J. Am. Ceram. Soc. 81,1310 (1998).

[17] G. B. Palmer, K. R. Poeppelmeier, and T. O. Mason, J. Solid State Chem. 134, 192 (1997).

[18] D. Calestani, S. C. Dhanabalan, M. Villani, L. Lazzarini, and A. Zappettini, Cryst. Eng. Comm. 16, 1696 (2014).

[19] L. Li, S. Chen, J. Kim, C. Xu, Y. Zhao, and K. J. Ziegler, J. Cryst. Growth 413, 31 (2015). 